\title{
The Synergic Effects of FDM 3D Printing Parameters on Mechanical Behaviors of Bronze Poly Lactic Acid Composites
}

\author{
Mahmoud Moradi ${ }^{1, *}$, Mojtaba Karami Moghadam ${ }^{1}$, Mahmoud Shamsborhan ${ }^{2,3}$ (1) and \\ Mahdi Bodaghi ${ }^{4, *}$ \\ 1 Department of Mechanical Engineering, Faculty of Engineering, Malayer University, \\ P.O. Box 65719-95863 Malayer, Iran; mojtaba.kmoghadam1991@gmail.com \\ 2 Department of Engineering, Mahabad Branch, Islamic Azad University, P.O. Box 59135-433 Mahabad, Iran; \\ m.shamsborhan@gmail.com \\ 3 Department of Mechanical Engineering, University of Zakho, Kurdistan Region, P.O. Box 12 Zakho, Iraq \\ 4 Department of Engineering, School of Science and Technology, Nottingham Trent University, \\ Nottingham NG11 8NS, UK \\ * Correspondence: moradi@malayeru.ac.ir (M.M.); mahdi.bodaghi@ntu.ac.uk (M.B.)
}

Received: 11 January 2020; Accepted: 29 January 2020; Published: 3 February 2020

\begin{abstract}
In this paper, the influence of layer thickness (LT), infill percentage (IP), and extruder temperature (ET) on the maximum failure load, thickness, and build time of bronze polylactic acid (Br-PLA) composites 3D printed by the fused deposition modeling (FDM) was investigated via an optimization method. PLA is a thermoplastic aliphatic polyester obtained from renewable sources, such as fermented plant starch, especially made by corn starch. The design of experiment (DOE) approach was used for optimization parameters, and 3D printings were optimized according to the applied statistical analyses to reach the best features. The maximum value of failure load and minimum value of the build time were considered as optimization criteria. Analysis of variance results identified the layer thickness as the main controlled variable for all responses. Optimum solutions were examined by experimental preparation to assess the efficiency of the optimization method. There was a superb compromise among experimental outcomes and predictions of the response surface method, confirming the reliability of predictive models. The optimum setting for fulfilling the first criterion could result in a sample with more than $1021 \mathrm{~N}$ maximum failure load. Finally, a comparison of maximum failure from PLA with Br-PLA was studied.
\end{abstract}

Keywords: 3D printing; FDM method; bronze polylactic acid composite; response surface method

\section{Introduction}

Always, time and accuracy are the most important factors for engineering appliances [1-4]. Recently, novel manufacturing methods are enabled to solve many long-term processes, such as molding and casting [5]. Additive manufacturing (AM) has been introduced for tackling this problem with many applications for creating samples with high accuracy [6]. One of the most significant approaches of AM methods is fused deposition modeling (FDM), which can create samples by 3D printing technology (Figure 1) [7]. In this technology, a layer is generated by melting the polymer with the printer head at a specific temperature [8-10]. In nature, many materials are renewable, and polylactic acid (PLA) is one of them, which is normally produced from corn starch. Also, PLA is a thermoplastic aliphatic polyester and is obtained from the sources of energy that aren't evacuated by consuming [11-13]. By combining PLA with flexible metal, such as bronze, the mechanical 
properties of the composite may be improved [14]. The FDM method has also been served by many researchers [15-17].

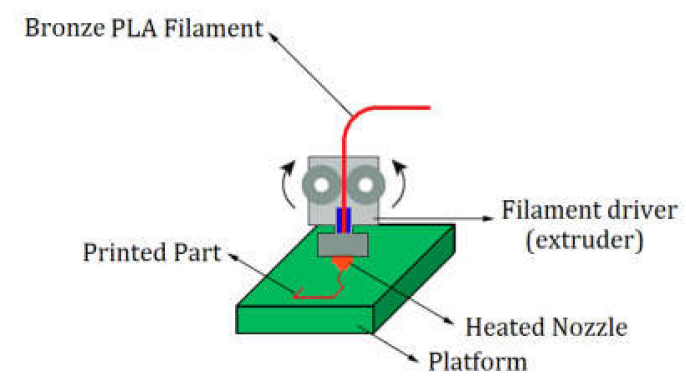

Figure 1. Schematic of 3D printing by the fused deposition modeling [18].

For instance, the influence of layer thickness on ABSP 400 samples was investigated by Padhi et al. [19]. Improving the quality of the parts made by two different methods was carried out by Gardan et al. [20]. The agents of the layer thickness, filling speed, extrusion speed, and line width on the built time and dimensions were investigated by Peng et al. [21]. Three responses were converted by a fuzzy inference system to a single output. The response surface methodology (RSM) was used to determine the relationship between four input parameters and comprehensive output. MATLAB software was also used to implement fitness function in the genetic algorithm. The results indicated that the proposed approach could effectively improve accuracy and efficiency in the FDM process. Sajan et al. carried out a study to improve the surface quality made with acrylonitrile butadiene styrene (ABS) filaments [22]. In this experiment, five parameters of the 3D printer were considered as input parameters, such as the printing speed, layer thickness, and infill percentage. Also, for the optimization of this experiment, they used the Taguchi method to reach the high quality of the surface. Results showed that the quality of the surface was improved in the XY and XZ planes. Gautam et al. [23] studied the compressive effect of ABS Kagome truss unit cell manufactured by the FDM. The properties of carbon-fiber-reinforced plastic (CFRP) manufactured composite parts were studied by Ning et al. [24]. They used the FDM method for fabricating CFRP composites, and the carbon fiber was added to composites filaments. In most traditional manufacturing methods, such as plastic molding [25-27], the tensile strength is acceptable due to the cohesion of materials. However, as one of the major disadvantages of additive manufacturing, they may result in weaker mechanical properties (electrical and thermal conductivity, optical transparency, and strength of printed parts). This paper attempted to improve the mechanical properties of FDM components by modifying the input parameters as well as using the design of experiment (DOE) method.

In the current research, the composite samples were produced by FDM 3D printing bronze polylactic acid (Br-PLA). Br-PLA tensile test sample was used to investigate the effects of the layer thickness, infill percentage, extruder temperature, and their interactions on mechanical properties, maximum failure load, thickness, build time of parts based on the DOE method. The main objective of this study was to fine-tune controlled variables to produce tough Br-PLA specimens, reduce part thickness, and shorten the build time of the printed parts. The build time data were recorded after printing the specimens by a digital timer. The tensile strength test determined the maximum failure load and elongation at break. Design-Expert V8 software was utilized for the statistical analysis of experimental data via the response surface method (RSM). The research objective was achieved by RSM and validated by experimental tests. Validation of the statistical model was confirmed by comparing the similar results with experimental data. Finally, the comparison of maximum failure from PLA with Br-PLA was investigated. 


\section{Experimental Design and Methodology}

\subsection{Response Surface Method}

In the AM, the response surface methodology (RSM) is a superb opportunity for recognizing a connection between the input and output parameters. In this study, based on three input parameters (layer thickness, infill percentage, extruder temperature) and three output parameters (maximum failure load, thickness, and build time of parts), an experimental investigation was carried out to create some 3D samples by using the RSM with least structure defects. Also, the statistical analysis was carried out on experimental data using the Design-Expert V8 software. The statistical analysis was designed based on the central composite design (CCD) full replication with three factors on five levels. Table 1 illustrates the levels of controlled factors. The designed experiments and results of tests are shown in Table 2.

Table 1. Levels of independent variables.

\begin{tabular}{ccccccccc}
\hline \multirow{2}{*}{ Variable } & \multirow{2}{*}{ Symbol } & \multirow{2}{*}{ Unit } & \multicolumn{7}{c}{ Levels } \\
\cline { 4 - 8 } & & & $\mathbf{- 2}$ & $\mathbf{- 1}$ & $\mathbf{0}$ & $\mathbf{1}$ & $\mathbf{2}$ \\
\hline Layer thickness (LT) & LT & mm & 0.15 & 0.25 & 0.35 & 0.45 & 0.55 \\
Infill percentage (IP) & IP & $\%$ & 15 & 25 & 35 & 45 & 55 \\
Extruder temperature (ET) & ET & C & 190 & 205 & 220 & 235 & 250 \\
\hline
\end{tabular}

Table 2. Design matrix and experiments results.

\begin{tabular}{|c|c|c|c|c|c|c|c|c|}
\hline \multirow[b]{2}{*}{ Ø્छ } & \multicolumn{3}{|c|}{ Input Variables } & \multicolumn{5}{|c|}{ Output Responses } \\
\hline & $\begin{array}{c}\text { Layer } \\
\text { Thickness } \\
\text { (mm) }\end{array}$ & $\begin{array}{c}\text { Infill } \\
\text { Percentage } \\
(\%)\end{array}$ & $\begin{array}{c}\text { Extruder } \\
\text { Temperature } \\
\left({ }^{\circ} \mathrm{C}\right)\end{array}$ & $\begin{array}{l}\text { Maximum } \\
\text { Failure Load } \\
\text { (N) }\end{array}$ & $\begin{array}{c}\text { Thickness } \\
(\mu \mathrm{m})\end{array}$ & $\begin{array}{l}\text { Build Time } \\
\text { (min) }\end{array}$ & $\begin{array}{l}\text { Elongation } \\
\text { at Break } \\
(\mathrm{mm})\end{array}$ & $\begin{array}{r}\text { Type of } \\
\text { Fracture }\end{array}$ \\
\hline 1 & 0.25 & 45.00 & 235.00 & 1015 & 1249 & 36 & 2.24 & Brittle \\
\hline 2 & 0.35 & 35.00 & 220.00 & 1025 & 1255 & 36 & 2.48 & Tough \\
\hline 3 & 0.45 & 45.00 & 235.00 & 1022 & 1258 & 37 & 2.35 & Brittle \\
\hline 4 & 0.35 & 15.00 & 220.00 & 1018 & 1252 & 36 & 2.26 & Brittle \\
\hline 5 & 0.15 & 35.00 & 220.00 & 805.8 & 521 & 25 & 1.50 & Brittle \\
\hline 6 & 0.35 & 35.00 & 220.00 & 1020 & 1256 & 35 & 2.25 & Brittle \\
\hline 7 & 0.35 & 35.00 & 220.00 & 1018 & 1255 & 36 & 2.20 & Brittle \\
\hline 8 & 0.45 & 25.00 & 235.00 & 1026 & 1258 & 36 & 2.64 & Brittle \\
\hline 9 & 0.35 & 55.00 & 220.00 & 1017 & 1247 & 36 & 3.45 & Tough \\
\hline 10 & 0.35 & 35.00 & 220.00 & 1019 & 1256 & 35 & 2.13 & Brittle \\
\hline 11 & 0.25 & 45.00 & 205.00 & 875 & 860 & 29 & 1.65 & Brittle \\
\hline 12 & 0.35 & 35.00 & 220.00 & 1014 & 1247 & 34 & 2.53 & Tough \\
\hline 13 & 0.45 & 25.00 & 205.00 & 862 & 905 & 30 & 1.40 & Brittle \\
\hline 14 & 0.45 & 45.00 & 205.00 & 882 & 910 & 31 & 1.52 & Brittle \\
\hline 15 & 0.25 & 25.00 & 235.00 & 895 & 917 & 32 & 1.89 & Brittle \\
\hline 16 & 0.35 & 35.00 & 220.00 & 1024 & 1257 & 36 & 2.75 & Brittle \\
\hline 17 & 0.25 & 25.00 & 205.00 & 981 & 923 & 33 & 2.26 & Brittle \\
\hline 18 & 0.35 & 35.00 & 250.00 & 1030 & 1270 & 39 & 2.55 & Tough \\
\hline 19 & 0.35 & 35.00 & 190.00 & 1017 & 1254 & 36 & 2.40 & Tough \\
\hline 20 & 0.55 & 35.00 & 220.00 & 1025 & 1272 & 38 & 2.25 & Brittle \\
\hline
\end{tabular}

\subsection{Experimental Work}

The mixture of two proper materials in the production of many composites has widely been used [28-35]. Mixed material has been detected to be effective in the 3D printing by a known approach, such as FDM. PLA is made from natural content with renewable features and also has good mechanical properties, which is noticed by many people who are environmental activists and persist in preventing many plastic products.

Simplify3D software was used to adapt the build parameters of samples. Simplify3D consists of an incredibly realistic pre-print simulation that allows checking the correct performance of the 3D printer 
before starting the printing process. The simulation contains information relating to the exact speeds, sequences, and settings, which are utilized for the printing. The tensile test sample was designed based on international standard ISO 527-2 by Solidworks software and imported in Simplify3D. Table 3 indicates definitions of FDM build parameters and shows fixed parameters that were kept constant for all experiments. The geometrical dimensions and internal pattern of the sample are represented in Figure 2. The machine used to print the samples was Sizan 3 (made in Sizan Pardazesh Kavir Company, Isfahan, Iran). Br-PLA filament (Kexcelled made in Hatchbox, Pomona, LA, USA) was installed on a specific part of the printer, and the filament was placed between two rollers and nozzle. By setting three input parameters on the printer, two rollers conducted the filament, and heating elements melted the materials. Then, the pressure was created by the rollers to push the half-melted material and deposit the first layer. The platform moved down and allowed the nozzle to print the next layers freely on the plane.

Table 3. FDM fixed parameters of the research.

\begin{tabular}{|c|c|c|c|c|}
\hline No & Build Parameters & Definition & Unit & Value \\
\hline 1 & Nozzle diameter & The diameter of the extruder nozzle. & $\mathrm{mm}$ & 0.45 \\
\hline 2 & Extrusion width & The desired single-outline width of the plastic extrusion. & $\mathrm{mm}$ & 0.45 \\
\hline 3 & Build orientation & $\begin{array}{l}\text { The angle between the central axis of the part and the } \\
\text { horizontal direction. }\end{array}$ & Degree & 45 \\
\hline 4 & Top solid layer & Number of solid layers required at the top of the part. & - & 6 \\
\hline 5 & Bottom solid layers & Required number of solid layers at the bottom of the part. & - & 6 \\
\hline 6 & $\begin{array}{l}\text { Default printing } \\
\text { speed }\end{array}$ & $\begin{array}{l}\text { Initial speed used for all printing movements } \\
\text { (modification may be added for cooling or } \\
\text { outline underspeed). }\end{array}$ & $\mathrm{mm} / \mathrm{min}$ & 3600 \\
\hline 7 & Retraction speed & $\begin{array}{l}\text { Extruder speed for the retraction movements typically } \\
\text { uses the highest speed the extruder can support. }\end{array}$ & $\mathrm{mm} / \mathrm{min}$ & 1800 \\
\hline 8 & Outline overlap & $\begin{array}{l}\text { Percentage of extrusion width that will overlap with } \\
\text { outline perimeters (ensures infill bonds to outline). }\end{array}$ & $\%$ & 15 \\
\hline
\end{tabular}
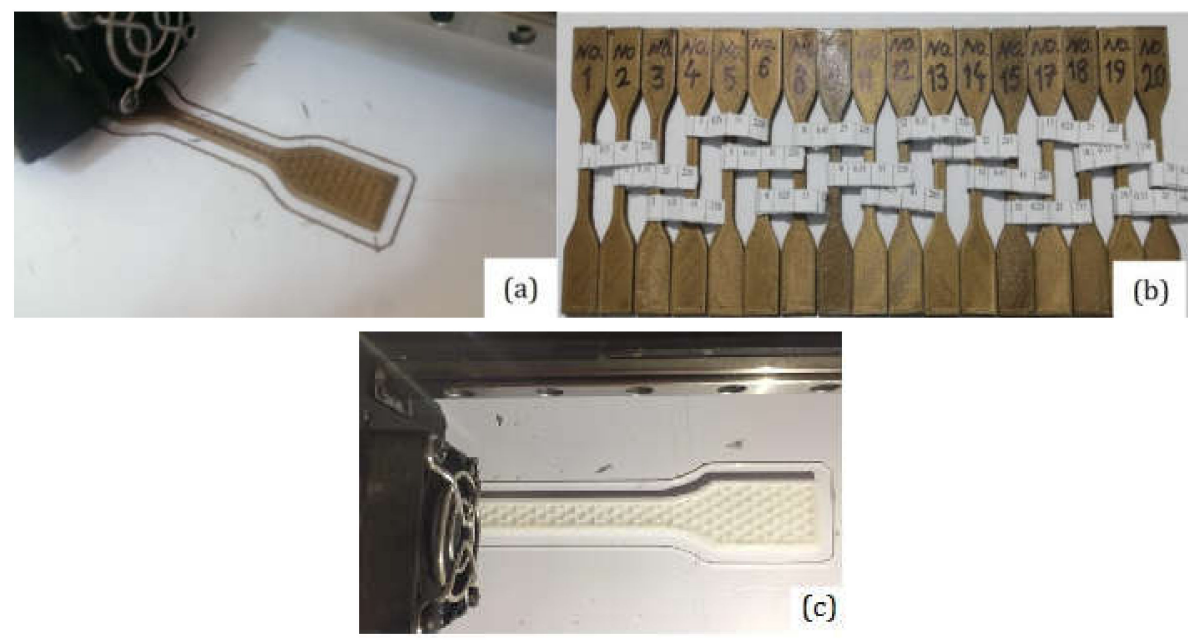

Figure 2. Cont. 


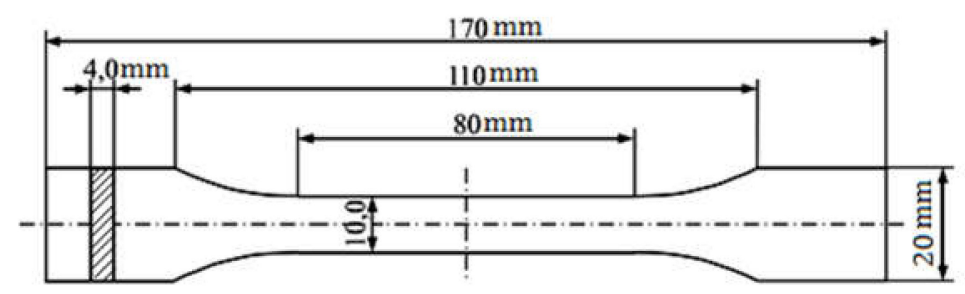

(d)

Figure 2. Geometrical dimensions and internal features of the sample. (a) 3D printing of bronze polylactic acid (Br-PLA) samples, (b) 3D printed samples, (c) 3D printing of polylactic acid (PLA) samples [18], (d) dimensions of the tensile test sample according to ISO 527-2.

The build time was measured by a digital timer after the printing of each sample; the maximum failure load was determined by the tensile strength test. The tensile strength tests were carried out with a universal testing machine based on ASTM D638 (ASTM International, Conshohocken. PA, USA). The brittle fracture of the samples (PLA and Br-PLA) on the universal testing machine is represented in Figure 3. Figure 4 also shows extension-force diagrams of samples \#2 and \#5. The results showed that the behavior of samples under load could be classified as a brittle and tough fracture. Almost $80 \%$ of the results in the design matrix had brittle fracture because PLA is relatively brittle under tensile loading. The fracture of brittle samples occurred at the elastic limit, while tough specimens showed the ability to undergo a low degree of plastic deformation before fracture. Therefore, samples with higher maximum failure load and elongation at the break had a tough fracture. However, a sudden brittle fracture is usually observed in samples at the elastic limit and in a lower failure load. Also, in the previous study [18], extruder temperature $\left(230^{\circ} \mathrm{C}\right)$, infill percentage $(16.86 \%)$, and layer thickness $(0.23 \mathrm{~mm})$ were selected as controlled parameters by optimum settings for PLA printed parts, and, in this study, the failure load was compared with Br-PLA.
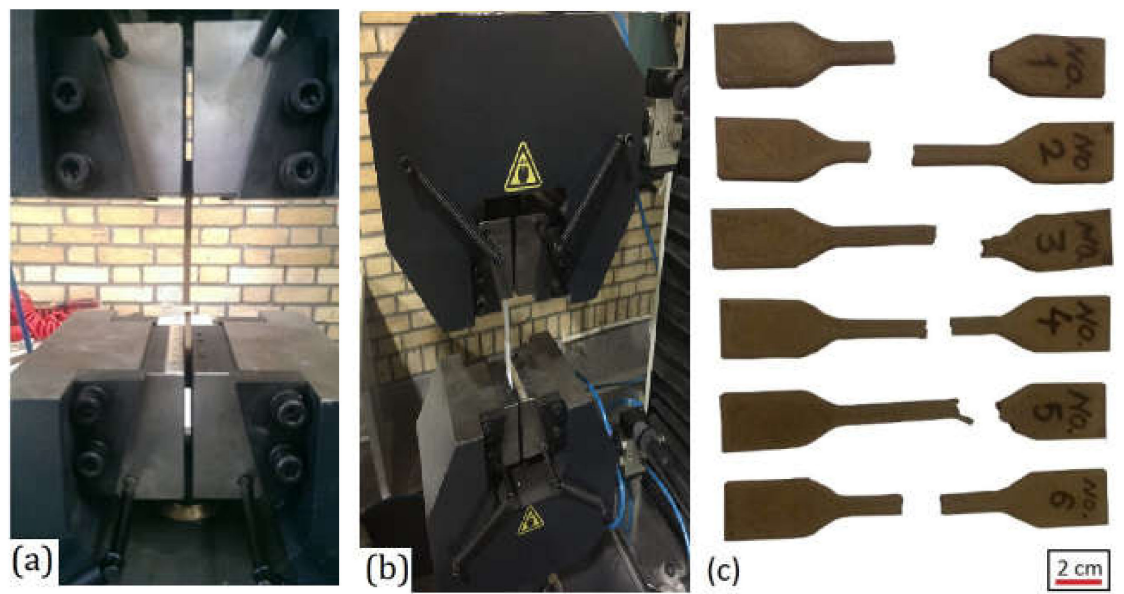

Figure 3. (a) Brittle fracture of the specimen (sample \#12 Br-PLA), (b) Brittle fracture of the optimum PLA specimen, (c) fracture of \#1 to \#6 samples. 


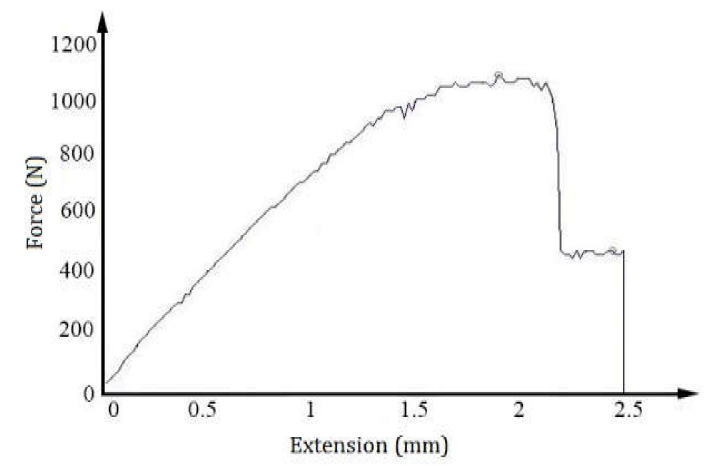

(a)

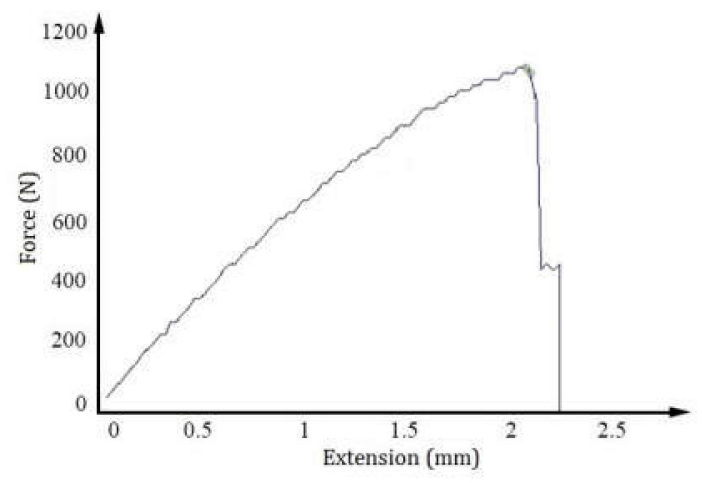

(b)

Figure 4. Extension-force diagrams of (a) sample \#2 and (b) sample \#4.

\section{Results and Discussion}

For improving the quality of the experiments and reducing the tests, the DOE approach was utilized. This method could be a link between input and output parameters with a logical and physical condition resulting from the primary experiment. For each of 20 samples in the first level of the experiment, the maximum failure load, thickness, and build time were measured. Design Expert V08 software, based on the regression equations and ANOVA table, sorted parameters for each output. In this stage of the experimental study, the results of the output parameters were analyzed. This composite was more flexible than the 3D printed PLA materials, but the failure load in the Br-PLA was less than PLA.

\subsection{Maximum Failure Load}

The ANOVA table showed that the layer thickness was the dominant controlled variable for the maximum failure load. Extruder temperature and infill percentage were also significant. Table 4 demonstrates the ANOVA results of the maximum failure load.

Table 4. Analysis of variance (ANOVA).

\begin{tabular}{cccccc}
\hline Source & Sum of Squares & Degrees of Freedom (DF) & Mean Square & F Value & $p$-Value \\
\hline Model & $4.22 \times 10^{13}$ & 7 & $6.02 \times 10^{12}$ & 5.972742 & 0.0155 \\
LT & $8.95 \times 10^{11}$ & 1 & $8.95 \times 10^{11}$ & 0.887652 & 0.3775 \\
IP & $1.16 \times 10^{12}$ & 1 & $1.16 \times 10^{12}$ & 1.150847 & 0.3190 \\
ET & $7.56 \times 10^{11}$ & 1 & $7.56 \times 10^{11}$ & 0.750007 & 0.4152 \\
LT $\times$ IP & $9.67 \times 10^{12}$ & 1 & $9.67 \times 10^{12}$ & 9.593505 & 0.0174 \\
LT $\times$ ET & $7.71 \times 10^{12}$ & 1 & $7.71 \times 10^{12}$ & 7.643659 & 0.0279 \\
LT $^{2}$ & $1.41 \times 10^{13}$ & 1 & $1.41 \times 10^{13}$ & 13.96848 & 0.0073 \\
ET $^{2}$ & $1.65 \times 10^{13}$ & 1 & $1.65 \times 10^{13}$ & 16.36513 & 0.0049 \\
Residual & $7.06 \times 10^{12}$ & 7 & $1.01 \times 10^{12}$ & & \\
Cor Total & $4.92 \times 10^{13}$ & 14 & & & \\
\hline \multicolumn{7}{c}{ Adj R-Squared $=0.7131$} & R-Squared $=0.8565$ &
\end{tabular}

Equation (1) is a predictive model of maximum failure load in terms of coded factors. Also, Equation (2) shows a predictive model of maximum failure load with respect to the actual values.

$$
\begin{gathered}
(\text { Maximum Failure Load })^{2.32}=9250115+473024.5 \mathrm{LT}-538606 \mathrm{IP}+434805.5 \mathrm{ET} \\
+4398413 \mathrm{LT} \times \mathrm{IP}+3926069 \mathrm{LT} \times \mathrm{ET}-3412710 \mathrm{LT}^{2}-3693896 \mathrm{ET}^{2} \\
(\text { Maximum Failure Load })^{2.32}=-1.4 \times 10^{8}-1.2 \times 10^{8} \mathrm{LT}^{-}-411791 \mathrm{IP}+1591377 \mathrm{ET} \\
+1099603 \mathrm{LT} \times \mathrm{IP}+654344.9 \mathrm{LT} \times \mathrm{ET}-8.5 \times 10^{7} \mathrm{LT}^{2}-4104.33 \mathrm{ET}^{2}
\end{gathered}
$$


The developed equation was useful to determine the relative significance of factors by comparing the factor coefficients. Also, Figure 5 shows the perturbation plot of the maximum failure load. The perturbation plot helped to compare the effect of all factors in the central point in the design space, as illustrated in Figure 5. The maximum failure load was plotted by changing only a factor over its range, while other factors were kept constant. Lines A, B, and C showed the sensitivity of maximum failure load to layer thickness, infill percentage, and extruder temperature, respectively. The perturbation plot disclosed increasing layer thickness and extruder temperature parameters that resulted in an increase in the mechanical strength of specimens. In addition, the plot showed that the maximum failure load depended almost equally on the extruder temperature. Figure 6a demonstrates the effects of the layer thickness and infill percentage on the maximum failure load. The IP had a very specific role in flexibility and tensile strength because by increasing the IP, the structure of 3D parts went to denser structure with lower porosity. Therefore, samples printed by high IP could resist the great tensile load, even though these samples did not have good flexibility properties. A 3D surface plot of maximum failure load with respect to the layer thickness and extruder temperature is shown in Figure $6 \mathrm{~b}$. It is clear that thinner samples under dramatic forces could not resist much. Figure 7 indicates the normal probability plot of the residuals to check for normality of residuals. The normal probability plot indicated whether residuals followed a normal distribution; in this case, the points followed a straight line. Some moderate scattering was also expected even with normal data.

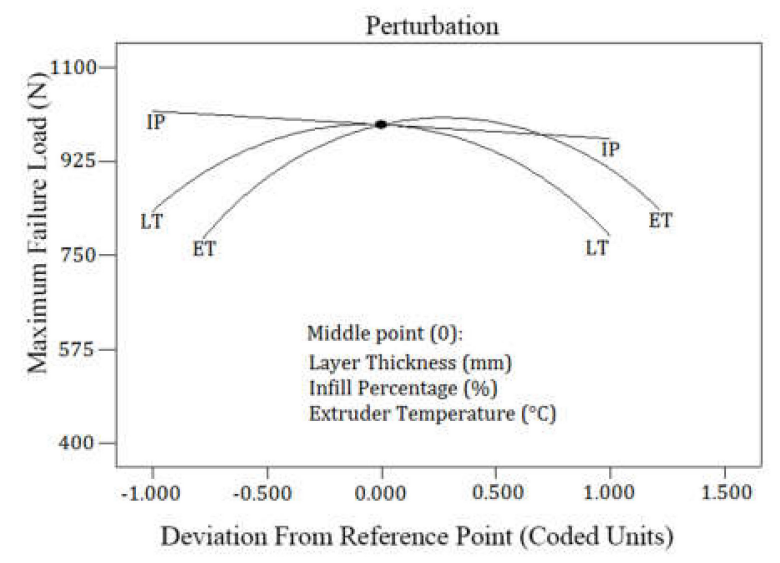

Figure 5. Perturbation plot of the maximum failure load.

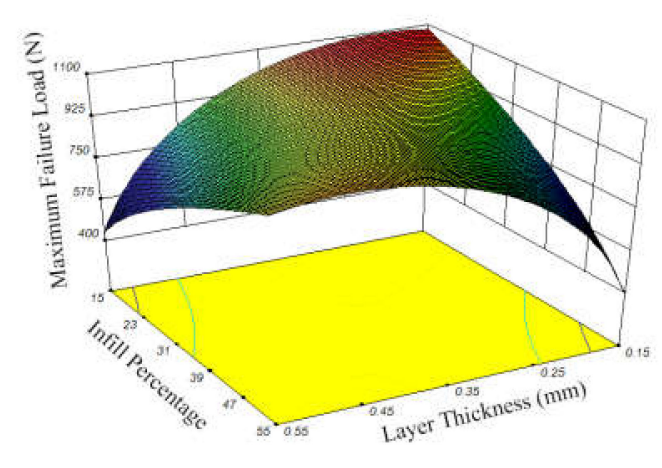

(a)

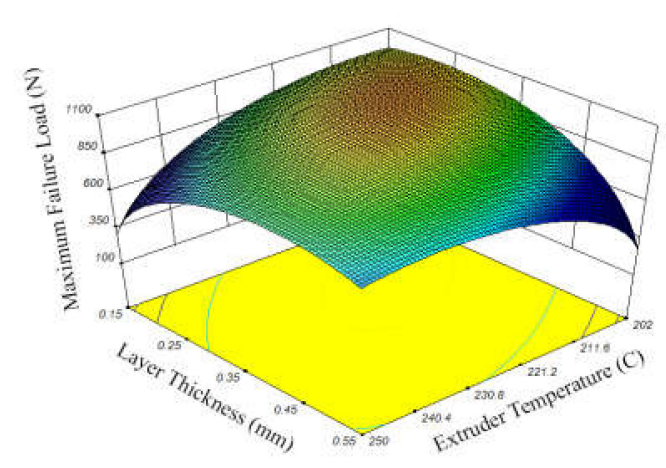

(b)

Figure 6. Cont. 


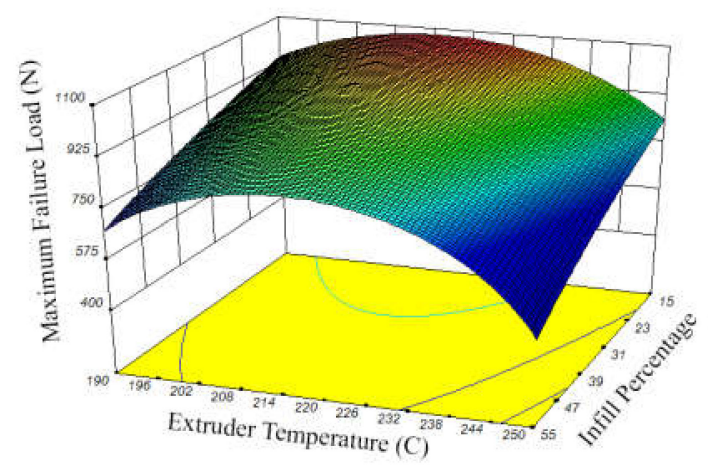

(c)

Figure 6. 3D surface plot of the maximum failure load with (a) infill percentage and layer thickness; (b) extruder temperature and layer thickness; (c) infill percentage and extruder temperature.

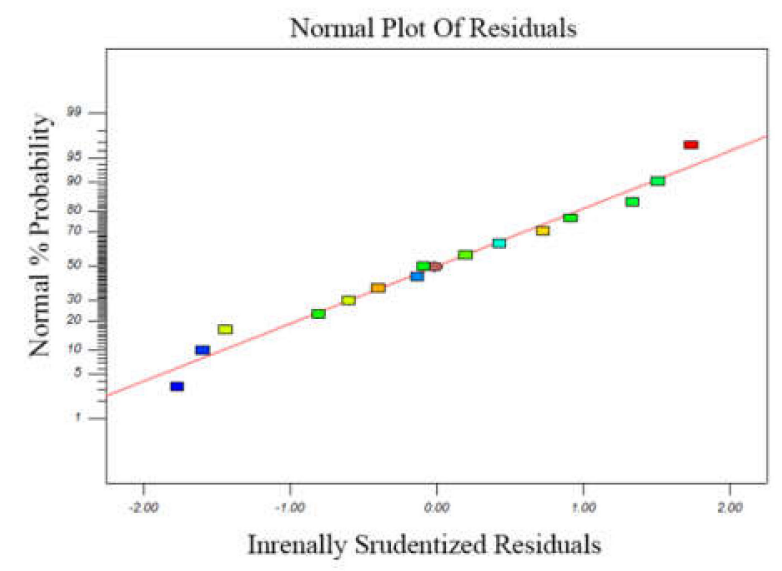

Figure 7. The normal plot of residuals of the maximum failure load.

\subsection{Build Time}

The ANOVA table revealed that Infill IP and IP2 of the printer were the most significant controlled variables for the build time. Table 5 demonstrates the ANOVA analysis for the build time. Equations (3) and (4) represent the final regression equation based on the coded values and actual values for the build time:

$$
\begin{aligned}
(\text { Build Time })^{-3} & =2.24976 \times 10^{-5}-1.20444 \times 10^{-5} \mathrm{IP}-2.51081 \times 10^{-7} \mathrm{ET} \\
& +3.00044 \times 10^{-5} \mathrm{IP}^{2}-1.27876 \times 10^{-5} \mathrm{ET}^{2} \\
& \\
(\text { Build Time })^{-3} & =-0.000548983-5.85298 \times 10^{-6} \mathrm{IP}+6.24335 \times 10^{-6} \mathrm{ET} \\
& +7.50109 \times 10^{-8} \mathrm{IP}^{2}-1.42085 \times 10^{-8} \mathrm{ET}^{2}
\end{aligned}
$$

Regression equations' terms had superb advantages in this study because many reasons, such as coded equation, could provide a suitable perception to physical parameters. Here, in the build time, LT, LP, and ET had a significant effect on the 3D printed samples. Due to Table 5, it was clear that LT was not very effective than either parameter and had a steady change. Results showed that when the IP rose, the built time increased. Also, when the ET rose, the built time reduced (Figure 8c) too. The probability plot in Figure 9 showed the residuals to illustrate the normality of residuals. In this diagram, the trend of the normal distribution in some particular samples was applied in a direct line. When the normal distribution became stable, the model was suitable for the build time, and it was clear that the normal distribution was close to the direct line. 
Table 5. Analysis of variance (ANOVA).

\begin{tabular}{cccccc}
\hline Source & Sum of Squares & Df & Mean Square & F Value & $p$-Value \\
\hline Model & $2.54 \times 10^{-9}$ & 5 & $5.09 \times 10^{-10}$ & 10.81049 & 0.0013 \\
IP & $5.8 \times 10^{-10}$ & 1 & $5.8 \times 10^{-10}$ & 12.33532 & 0.0066 \\
ET & $2.52 \times 10^{-13}$ & 1 & $2.52 \times 10^{-13}$ & 0.005361 & 0.9432 \\
$\mathrm{IP}^{2}$ & $1.09 \times 10^{-9}$ & 1 & $1.09 \times 10^{-9}$ & 23.14339 & 0.0010 \\
$\mathrm{ET}^{2}$ & $1.98 \times 10^{-10}$ & 1 & $1.98 \times 10^{-10}$ & 4.203745 & 0.0706 \\
Residual & $4.23 \times 10^{-10}$ & 9 & $4.7 \times 10^{-11}$ & & \\
Cor Total & $2.97 \times 10^{-9}$ & 14 & & \\
\hline \multicolumn{7}{c}{ R-Squared $=0.7779$} & Adj R-Squared $=0.8572$ & \\
\hline
\end{tabular}

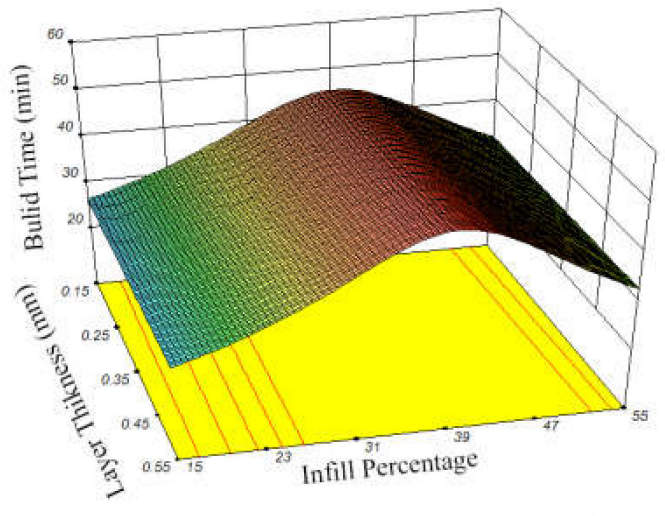

(a)

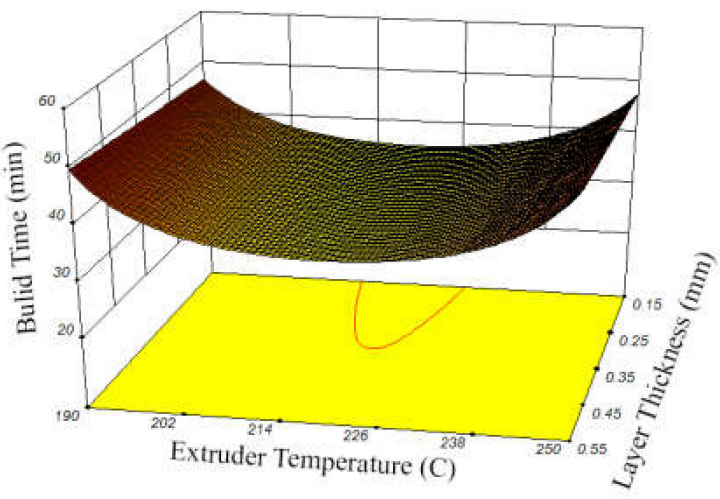

(b)

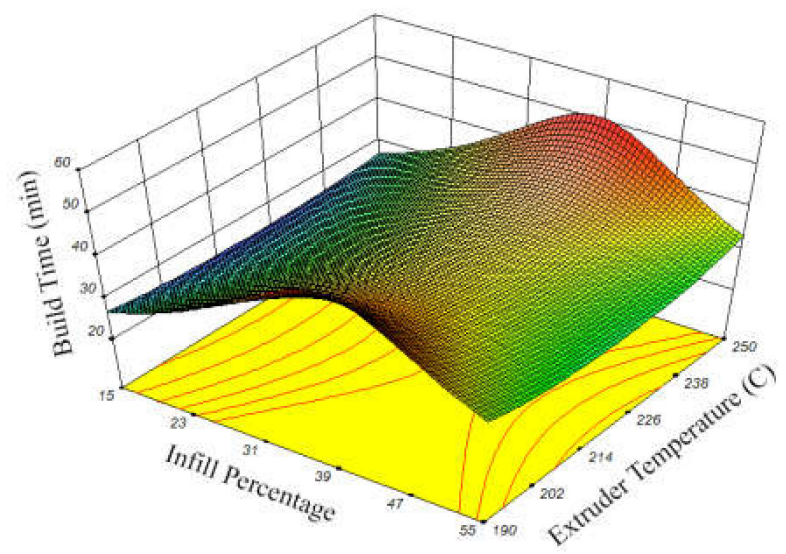

(c)

Figure 8. 3D surface plot of the build time with (a) infill percentage and layer thickness; (b) extruder temperature and layer thickness; (c) infill percentage and extruder temperature. 


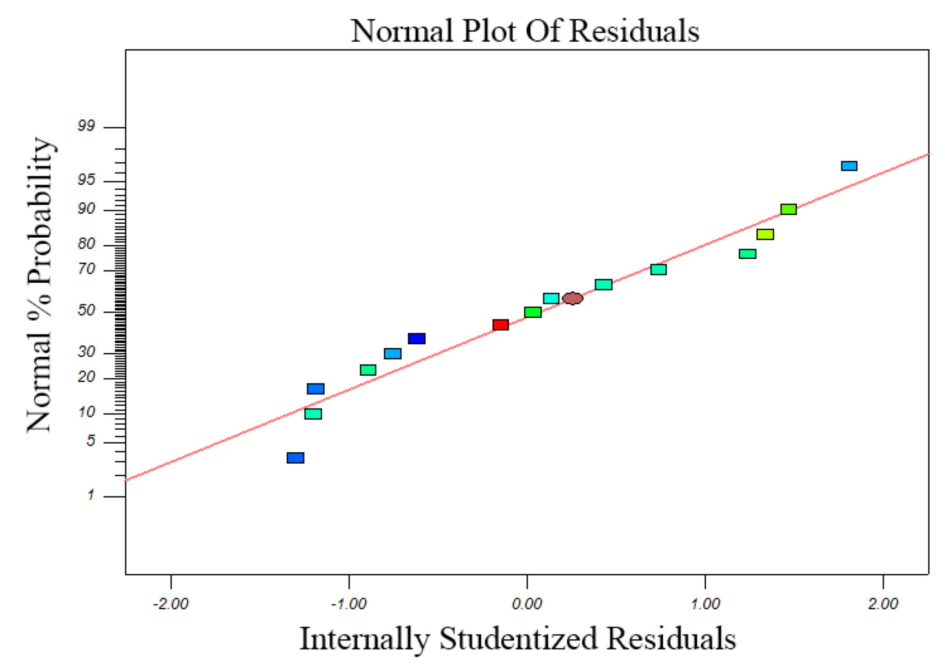

Figure 9. The normal plot of residuals of the build time.

\subsection{Thickness}

Table 6 depicts the ANOVA output and input parameters outcome for one of the important and significant features of samples. It could be found that LT and ET were the most effective variables. Part thickness' predictive model in terms of coded factors and actual amounts are represented in Equations (5) and (6), respectively.

$$
\begin{gathered}
(\text { Thickness })^{0.86}=340.4628+97.46882 \mathrm{LT}-5.40253 \mathrm{IP}-58.3206 \mathrm{ET}-210.432 \mathrm{IP} \times \mathrm{ET} \\
(\text { Thickness })^{0.86}=-3285.51+4990.265 \mathrm{LT}+64.80622 \mathrm{IP}+15.92595 \mathrm{ET}-0.35072 \mathrm{IP} \times \mathrm{ET}
\end{gathered}
$$

Table 6. Analysis of variance (ANOVA).

\begin{tabular}{cccccc}
\hline Source & Sum of Squares & Df & Mean Square & F Value & $p$-Value \\
\hline Model & $94,256.12$ & 7 & $13,465.16$ & 4.82262 & 0.0274 \\
LT & $38,000.68$ & 1 & $38,000.68$ & 13.61015 & 0.0078 \\
IP & 116.7494 & 1 & 116.7494 & 0.041814 & 0.8438 \\
ET & $13,605.18$ & 1 & $13,605.18$ & 4.872769 & 0.0630 \\
IP $\times$ ET & $22,140.75$ & 1 & $22,140.75$ & 7.929828 & 0.0259 \\
Residual & $19,544.59$ & 7 & 2792.084 & & \\
Cor Total & $113,800.7$ & 14 & & \\
\hline \multicolumn{7}{c}{ Adj R-Squared $=0.6565$} & \multicolumn{7}{c}{ Rquared $=0.8282$} \\
\hline
\end{tabular}

The excellent R-squared and adjusted R-squared of the predictive model confirmed that the model was immensely reliable. As shown in Figure 10a, by raising the infill percentage, the amount of the thickness increased. Figure $10 \mathrm{~b}$ revealed that with raising the layer thickness and the extruder temperature, the thickness increased. The reason for this phenomenon was that when ET and LT grew up, the material printed rose. That is because the LT always equated with more material injection. Therefore, the amount of thickness increased. Figures 11 and 12 show the perturbation plot and normal plot of residuals of the thickness, respectively. 


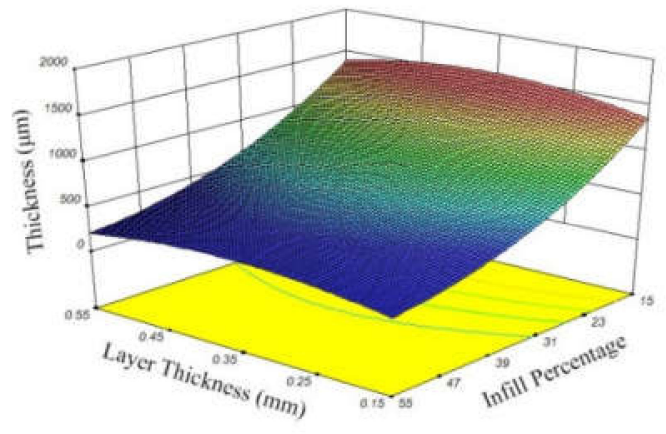

(a)

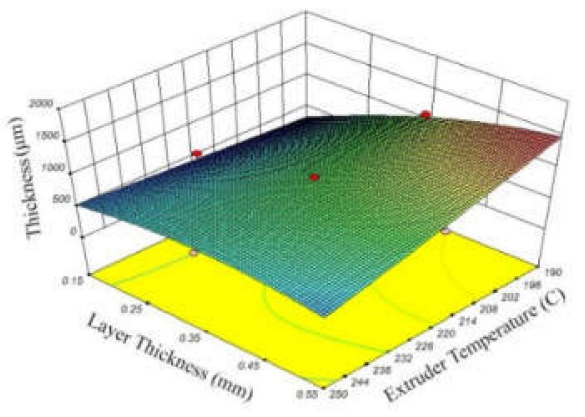

(b)

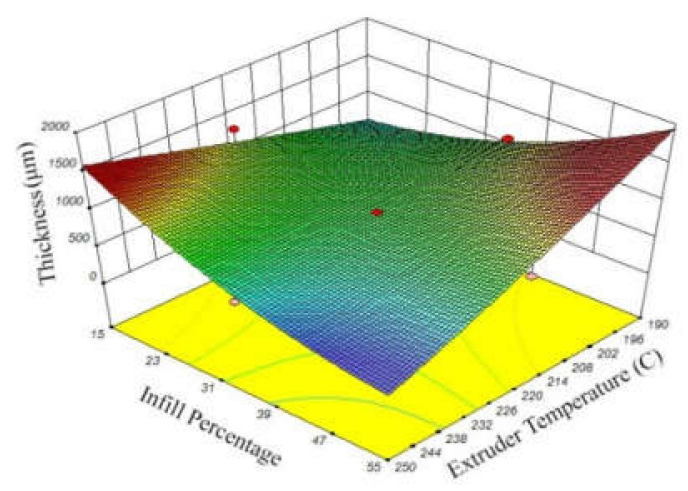

(c)

Figure 10. 3D surface plot of the maximum width with (a) infill percentage and layer thickness; (b) extruder temperature and layer thickness; (c) infill percentage and extruder temperature.

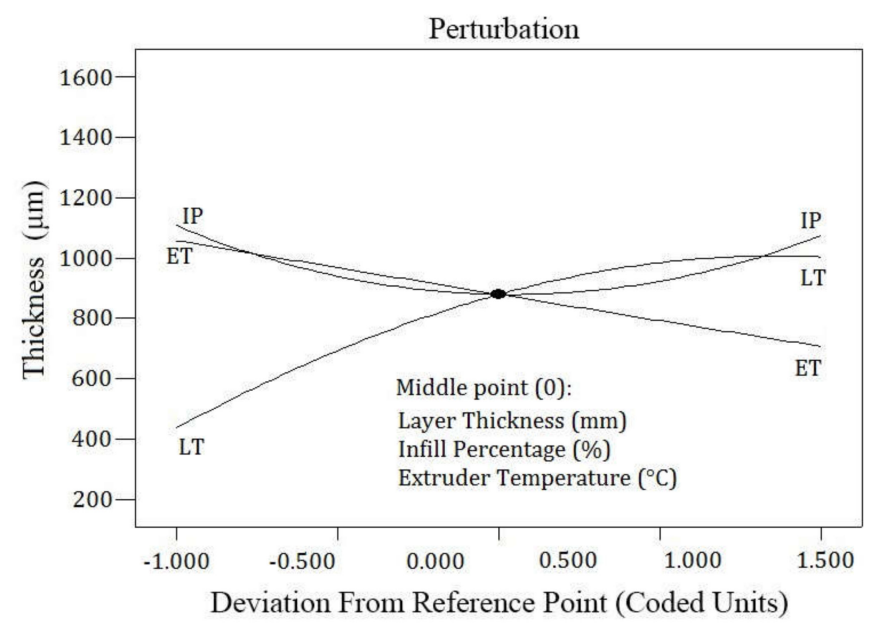

Figure 11. Perturbation plot of the maximum width. 


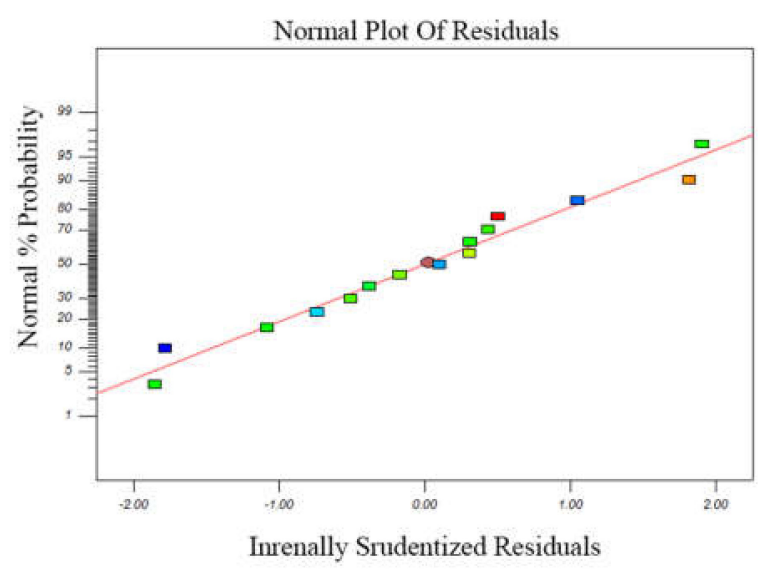

Figure 12. The normal plot of residuals of thickness.

\section{Numerical Optimization}

In this study, for the sake of numerical optimization, three criteria were evaluated. Three criteria of these experiments are shown in Table 7. Table 8 shows the predicted optimum results and experimental validation for Br-PLA 3D printing samples. Some parameters of physical and mechanical properties were considered as output parameters because it is essential for manufacturing samples with good conditions, such as proper resist from tensile strengths and adequate thickness. The optimization method provided an efficient condition to produce these samples. As a matter of fact, the suitable portion of each material was very important in the composite structure. Br-PLA consisted of two phases with a ratio of $35 \%$ to $65 \%$, wherein the variation of the 3D printing input parameters played an important role in producing samples without any defects. The strong samples with the least deformation were the main goal of this article. Based on Table 8, the predicted optimum results and experimental validation were very close together and showed slight errors between them. Overly diagram in Figure 13 illustrates two parts of optimization in which substantial region in input parameters was relevant by output parameters. It means that the variation of each parameter had a significant role in output results. Also, in Figure 14, the results for the higher tensile strength in optimum samples are shown. In a previous study [18], in the PLA 3D printing samples, the maximum failure load was reported more than Br-PLA samples because the composite structure had the more particle's space, while, in Br-PLA, the metal component took up more space than PLA structure. Therefore, the PLA parts had more resistance in the tensile strength test.

Table 7. Constraints and criteria of input parameters and responses.

\begin{tabular}{|c|c|c|c|c|c|c|c|}
\hline Parameters/Responses & Name & Goal & $\begin{array}{c}\text { Lower } \\
\text { Limit }\end{array}$ & $\begin{array}{l}\text { Upper } \\
\text { Limit }\end{array}$ & $\begin{array}{c}\text { Lower } \\
\text { Weight }\end{array}$ & $\begin{array}{c}\text { Upper } \\
\text { Weight }\end{array}$ & Importance \\
\hline \multirow{3}{*}{ 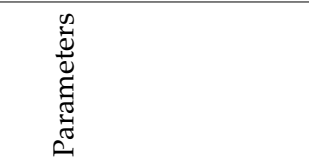 } & Layer thickness & is in rang & 0.15 & 0.55 & 1 & 1 & - \\
\hline & Infill percentage & is in rang & 15 & 55 & 1 & 1 & - \\
\hline & Extruder temperature & is in rang & 190 & 250 & 1 & 1 & - \\
\hline \multirow{9}{*}{$\begin{array}{l}\mathscr{D} \\
\tilde{0} \\
0 \\
\tilde{D} \\
\mathscr{D} \\
\simeq\end{array}$} & Maximum failure load & maximize & 711.2 & 1066.8 & 1 & 1 & 5 \\
\hline & Maximum width & is in rang & 429.5 & 1420.32 & 1 & 1 & 3 \\
\hline & Build time & minimize & 25 & 52 & 1 & 1 & 5 \\
\hline & Maximum failure load & maximize & 711.2 & 1066.8 & 1 & 1 & 3 \\
\hline & Maximum width & maximize & 429.5 & 1420.32 & 1 & 1 & 3 \\
\hline & Build time & minimize & 25 & 52 & 1 & 1 & 2 \\
\hline & Maximum failure load & maximize & 711.2 & 1066.8 & 1 & 1 & 2 \\
\hline & Maximum width & maximize & 429.5 & 1420.32 & 1 & 1 & 3 \\
\hline & Build time & minimize & 25 & 52 & 1 & 1 & 5 \\
\hline
\end{tabular}


Table 8. Predicted optimum results and experimental validation.

\begin{tabular}{|c|c|c|c|c|c|c|c|c|}
\hline \multirow[b]{2}{*}{ Solution } & \multicolumn{3}{|c|}{ Optimum Input Parameters } & \multirow{2}{*}{ Desirability } & & \multicolumn{3}{|c|}{ Output Responses } \\
\hline & LT & IP & ET & & & $\begin{array}{l}\text { Maximum Failure Load } \\
\text { (N) }\end{array}$ & $\begin{array}{l}\text { Thickness } \\
(\mu \mathrm{m})\end{array}$ & $\begin{array}{l}\text { Build Time } \\
\text { (min) }\end{array}$ \\
\hline \multirow{3}{*}{1} & \multirow{3}{*}{0.23} & \multirow{3}{*}{15.15} & \multirow{3}{*}{222.73} & \multirow{3}{*}{0.97} & Actual & 1016 & 1247 & 36 \\
\hline & & & & & Predicted & 950 & 1110 & 34 \\
\hline & & & & & Error\% & 6.49 & 10.98 & 5.55 \\
\hline \multirow{3}{*}{2} & \multirow{3}{*}{0.2} & \multirow{3}{*}{15.15} & \multirow{3}{*}{219.13} & \multirow{3}{*}{0.85} & Actual & 1007 & 1234 & 34 \\
\hline & & & & & Predicted & 944 & 1099 & 33 \\
\hline & & & & & Error\% & 6.25 & 10.94 & 2.94 \\
\hline \multirow{3}{*}{3} & \multirow{3}{*}{0.25} & \multirow{3}{*}{15.20} & \multirow{3}{*}{222.82} & \multirow{3}{*}{0.78} & Actual & 1021 & 1257 & 36 \\
\hline & & & & & Predicted & 1013 & 1237 & 35 \\
\hline & & & & & Error\% & 0.78 & 1.59 & 2.77 \\
\hline
\end{tabular}

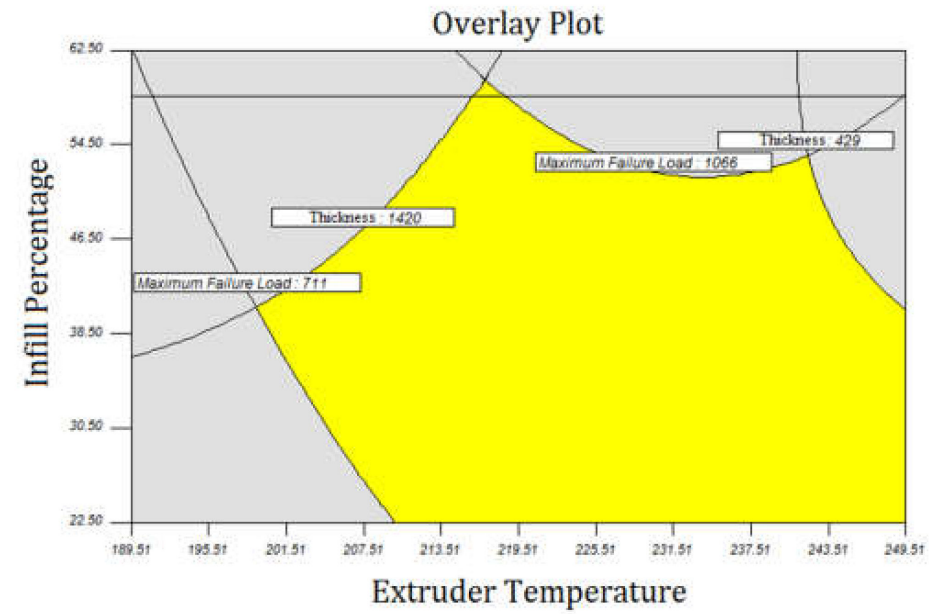

(a)

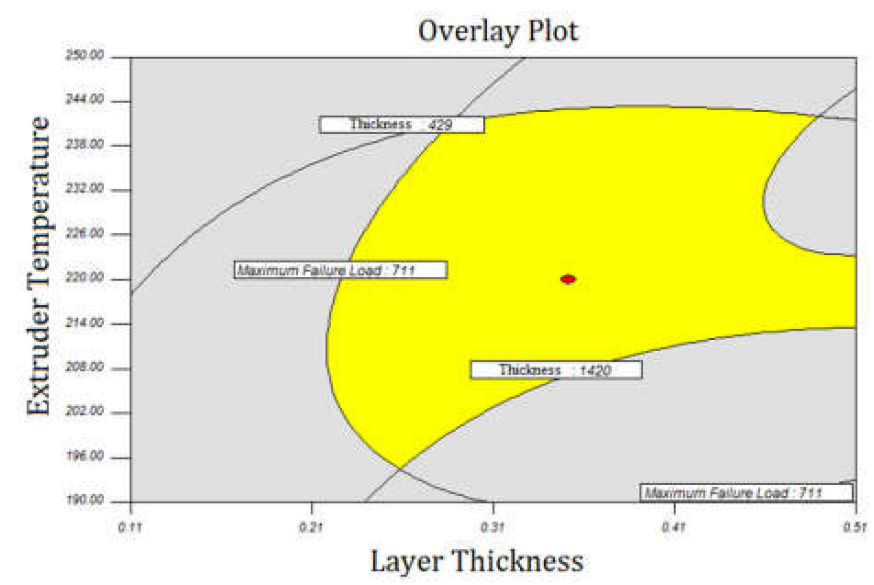

(b)

Figure 13. Overlay plot of 3D printing optimization with (a) infill percentage and extruder temperature; (b) extruder temperature and layer thickness. 


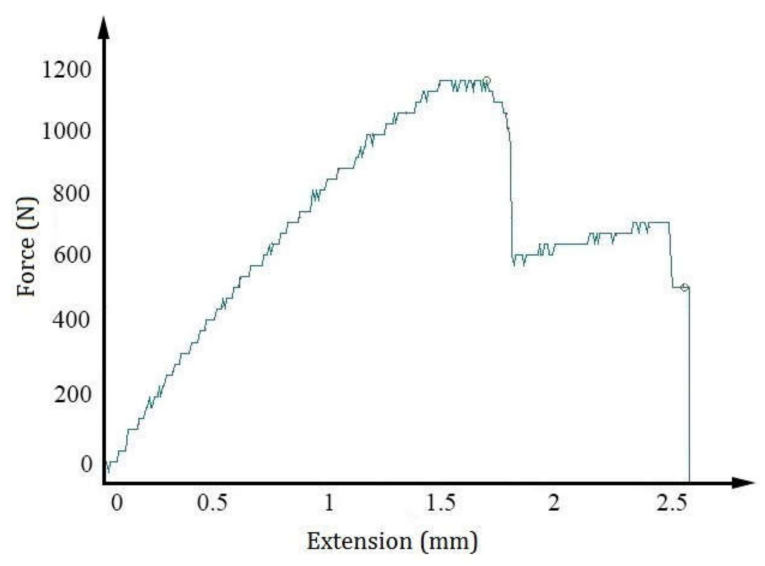

Figure 14. Extension-force diagram of the specimen for solution 3.

\section{Comparison of PLA and Br-PLA 3D Printed Samples}

In this part, the comparison of PLA and Br-PLA 3D printed samples were investigated. From Section 4, which is related to the extension-force result of the specimen for solution 3 of Br-PLA composite and also PLA optimum sample in the previous study [18], respectively, it was clear that the tensile strength of PLA was higher than the Br-PLA composite. This phenomenon happened because of two reasons. Firstly, when the Br-PLA composite parts were printed, the infill percentage was less than PLA printed parts in the constant situation and input parameters. The second reason was that PLA is a single material and has the good connection between its particles, whereas, in the Br-PLA sample, because two materials are used, the connection of particles are weaker than PLA sample, but the flexibility of the Br-PLA part is higher than the PLA part [36].

\section{Conclusions}

FDM 3D printing method for producing the Br-PLA samples was improved by the DOE approach and considering the significant input parameters (infill percentage, extruder temperature, and layer thickness) for each output parameter (maximum failure load, build time, and sample thickness). In the continuation of the article, some of the conclusions are mentioned:

(1) The results showed that the mechanical properties (maximum failure load) of the samples improved as the layer thickness increased because the higher layer thickness could resist a more tensile load.

(2) Results indicated that when the infill percentage increased, the mechanical properties of pieces improved because of the increase in the adhesion of components.

(3) The optimized printed Br-PLA specimen with a layer thickness of $0.25 \mathrm{~mm}, 15.20$ infill percentage, and $222.82{ }^{\circ} \mathrm{C}$ extruder temperature could resist more than $1000 \mathrm{~N}$.

(4) For producing a suitable sample with good mechanical and economical features, middle extruder temperatures and low infill percentages must be considered. Because in the Br-PLA 3D samples, the heavy and rough samples might not be used very much, and the heavier samples are costly.

(5) In the PLA 3D printing samples, the maximum failure load was reported more than Br-PLA samples, and that is because the composite structure has the more particle's space, and in Br-PLA, the metal component takes up more space than PLA structure.

Author Contributions: Conceptualization, M.M.; methodology, M.M. and M.K.M.; software, M.K.M. and M.S.; validation, M.M., M.K.M., and M.B.; investigation, M.M., M.K.M., and M.B.; resources, M.M.; writing-original draft preparation, M.M., M.K.M., and M.B.; writing-review and editing, M.M., M.K.M., M.S., and M.B.; supervision, M.M.; project administration, M.M. All authors have read and agreed to the published version of the manuscript.

Funding: This research received no external funding. 
Conflicts of Interest: The authors declare no conflict of interest.

\section{References}

1. Groover, M.P. Fundamentals of Modern Manufacturing: Materials, Processes, and Systems, 4th ed.; John Wiley \& Sons, Inc.: Hoboken, NJ, USA, 2010.

2. Casalino, G.; Moradi, M.; Moghadam, M.K.; Khorram, A.; Perulli, P. Experimental and Numerical Study of AISI 4130 Steel Surface Hardening by Pulsed Nd: YAG Laser. Materials 2019, 12, 3136. [CrossRef] [PubMed]

3. Moradi, M.; KaramiMoghadam, M. High power diode laser surface hardening of AISI 4130; statistical modelling and optimization. Opt. Laser Technol. 2019, 111, 554-570. [CrossRef]

4. Gibson, I.; Rosen, D.; Stucker, B. Additive Manufacturing Technologies: 3D Printing, Rapid Prototyping, and Direct Digital Manufacturing, 2nd ed.; Springer: Berlin, Germany, 2015.

5. Ahn, S.; Montero, M.; Odell, D.; Roundy, S.; Wright, P.K. Anisotropic material properties of fused deposition modeling ABS. Rapid Prototyp. J. 2002, 8, 248-257. [CrossRef]

6. Liu, X.; Zhang, M.; Li, S.; Si, L.; Peng, J.; Hu, Y. Mechanical property parametric appraisal of fused deposition modeling parts based on the gray Taguchi method. Int. J. Adv. Manuf. Technol. 2017, 89, 2387-2397. [CrossRef]

7. Dong, G.; Wijaya, G.; Tang, Y.; Zhao, Y.F. Optimizing process parameters of fused deposition modeling by Taguchi method for the fabrication of lattice structures. Add. Manuf. 2018, 19, 62-72. [CrossRef]

8. Mahmood, S.; Qureshi, A.J.; Talamona, D. Taguchi based process optimization for dimension and tolerance control for fused deposition modelling. Add. Manuf. 2018, 21, 183-190. [CrossRef]

9. Milosevic, M.; Stoof, D.; Pickering, K.L. Characterizing the Mechanical Properties of Fused Deposition Modelling Natural Fiber Recycled Polypropylene Composites. J. Compos. Sci. 2017, 1, 7. [CrossRef]

10. Pandey, P.M.; Thrimurthulu, K.; Reddy, N.V. Optimal part deposition orientation in FDM by using a multicriteria genetic algorithm. Int. J. Prod. Res. 2004, 42, 4069-4089. [CrossRef]

11. El Magri, A.; El Mabrouk, K.; Vaudreuil, S.; Ebn Touhami, M. Mechanical properties of CF-reinforced PLA parts manufactured by fused deposition modeling. J. Thermopl. Compos. Mater. 2019. [CrossRef]

12. Moura, N.K.; Siqueira, I.A.W.B.; Machado, J.P.B.; Kido, H.W.; Avanzi, I.R.; Rennó, A.C.M.; Trichês, E.S.; Passador, F.R. Production and Characterization of Porous Polymeric Membranes of PLA/PCL Blends with the Addition of Hydroxyapatite. J. Compos. Sci. 2019, 3, 45. [CrossRef]

13. Backes, E.H.; Pires, L.N.; Costa, L.C.; Passador, F.R.; Pessan, L.A. Analysis of the Degradation During Melt Processing of PLA/Biosilicate ${ }^{\circledR}$ Composites. J. Compos. Sci. 2019, 3, 52. [CrossRef]

14. Galantucci, L.M.; Lavecchia, F.; Percoco, G. Quantitative analysis of a chemical treatment to reduce roughness of parts fabricated using fused deposition modelling. CIRP Ann. Manuf. Technol. 2010, 59, 247-250. [CrossRef]

15. Sood, A.K.; Ohdar, R.K.; Mahapatra, S.S. Experimental investigation and empirical modelling of FDM process for compressive strength improvement. J. Adv. Res. 2012, 3, 81-90. [CrossRef]

16. Rao, V.; Rai, D.P. Optimization of fused deposition modelling process using teaching-learning based optimization algorithm. Eng. Sci. Technol. Int. J. 2016, 19, 587-603. [CrossRef]

17. Austin, P.; Robert, M.; Alexander, G.D.; Jack, G. Graphene and Carbon Nanotube PLA Composite Feedstock Development for Fused Deposition Modeling; University of Tennessee Honors Thesis Projects: Knoxville, TN, USA, 2016.

18. Moradi, M.; Meiabadi, S.; Kaplan, A. 3D Printed Parts with Honeycomb Internal Pattern by Fused Deposition Modelling; Experimental Characterization and Production Optimization. Met. Mater. Int. 2019, 25, 1312-1325. [CrossRef]

19. Padhi, S.K.; Sahu, R.K.; Mahapatra, S.S.; Das, H.C.; Sood, A.K.; Patro, B.; Mondal, A.K. Optimization of fused deposition modeling process parameters using a fuzzy inference system coupled with Taguchi philosophy. Adv. Manuf. 2017, 5, 231-242. [CrossRef]

20. Gardan, J.; Makke, A.; Recho, N. Improving the fracture toughness of 3D printed thermoplastic polymers by fused deposition modeling. Int. J. Fract. 2018, 210, 1-15. [CrossRef]

21. Peng, A.; Xiao, X.; Yue, R. Process parameter optimization for fused deposition modeling using response surface methodology combined with fuzzy inference system. Int. J. Adv. Manuf. Technol. 2014, 73, 87-100. [CrossRef] 
22. Sajan, N.; John, T.D.; Singh, N.K. An investigation on circularity error of components processed on Fused Deposition Modeling (FDM). Mater. Today Proc. 2018, 5, 1327-1334. [CrossRef]

23. Gautam, R.; Idapalapati, S.; Feih, S. Printing and characterisation of Kagome lattice structures by fused deposition modelling. Mater. Des. 2018, 137, 266-275. [CrossRef]

24. Ning, F.; Cong, W.; Wei, J.; Wang, S. Additive Manufacturing of CFRP Composites Using Fused Deposition Modeling: Effects of Carbon Fiber Content and Length. In Proceedings of the ASME 2015 International Manufacturing Science and Engineering Conference, Charlotte, NC, USA, 8-12 June 2015.

25. Ghennai, W.; Boussaid, O.; Bendjama, H.; Haddag, B.; Nouari, M. Experimental and numerical study of DC04 sheet metal behaviour-plastic anisotropy identification and application to deep drawing. Int. J. Adv. Manuf. Technol. 2019, 100, 361-371. [CrossRef]

26. Taherzadehboroujeni, M.; Kalhor, R.; Fahs, G.B.; Moore, R.B.; Case, S.W. Accelerated testing method to estimate the long-term hydrostatic strength of semi-crystalline plastic pipes. Poly. Eng. Sci. 2019. [CrossRef]

27. Komarasamy, M.; Wang, T.; Liu, K.; Reza-Nieto, L.; Mishra, R.S. Hierarchical multi-phase microstructural architecture for exceptional strength-ductility combination in a complex concentrated alloy via high-temperature severe plastic deformation. Scr. Mater. 2019, 162, 38-43. [CrossRef]

28. Yuan, S.; Shen, F.; Chua, C.K.; Zhou, K. Polymeric composites for powder-based additive manufacturing. Mater. Appl. Progr. Polym. Sci. 2019, 91, 141-168. [CrossRef]

29. Naranjo-Lozada, J.; Ahuett-Garza, H.; Orta-Castañón, P.; Verbeeten, W.M.; Sáiz-González, D. Tensile properties and failure behavior of chopped and continuous carbon fiber composites produced by additive manufacturing. Add. Manuf. 2019, 26, 227-241. [CrossRef]

30. Griffiths, R.J.; Perry, M.E.; Sietins, J.M.; Zhu, Y.; Hardwick, N.; Cox, C.D.; Rauch, H.A.; Hang, Z.Y. A Perspective on Solid-State Additive Manufacturing of Aluminum Matrix Composites Using MELD. J. Mater. Eng. Perform. 2019, 28, 648-656. [CrossRef]

31. Dickson, A.N.; Dowling, D.P. Enhancing the bearing strength of woven carbon fibre thermoplastic composites through additive manufacturing. Compos. Struct. 2019, 212, 381-388. [CrossRef]

32. Singh, N.; Singh, R.; Ahuja, I.P.S.; Farina, I.; Fraternali, F. Metal matrix composite from recycled materials by using additive manufacturing assisted investment casting. Compos. Struct. 2019, 207, 129-135. [CrossRef]

33. Sekar, V.; Fouladi, M.H.; Namasivayam, S.N.; Sivanesan, S. Additive Manufacturing: A Novel Method for Developing an Acoustic Panel Made of Natural Fiber-Reinforced Composites with Enhanced Mechanical and Acoustical Properties. J. Eng. 2019, 2019, 4546863. [CrossRef]

34. Feng, Y.C.; Bodaghi, M.; Liao, W.H. Numerical/experimental assessment of 3D-printed shape-memory polymeric beams. J. Appl. Polym. Sci. 2019, 136, 47422. [CrossRef]

35. Bodaghi, M.; Damanpack, A.R.; Hu, G.F.; Liao, W.H. Large deformations of soft metamaterials fabricated by 3D printing. Mater. Des. 2017, 131, 81-91. [CrossRef]

36. Kuznetsov, V.E.; Solonin, A.N.; Urzhumtsev, O.D.; Schilling, R.; Tavitov, A.G. Strength of PLA Components Fabricated with Fused Deposition Technology Using a Desktop 3D Printer as a Function of Geometrical Parameters of the Process. Polymers 2018, 10, 313. [CrossRef] [PubMed]

(C) 2020 by the authors. Licensee MDPI, Basel, Switzerland. This article is an open access article distributed under the terms and conditions of the Creative Commons Attribution (CC BY) license (http://creativecommons.org/licenses/by/4.0/). 